\title{
BMJ Open Kids in Communities Study (KiCS) study protocol: a cross-sectional mixed-methods approach to measuring community-level factors influencing early child development in Australia
}

\author{
Sharon Goldfeld, ${ }^{1,2,3}$ Karen Villanueva, ${ }^{2,3,4}$ Robert Tanton, ${ }^{5}$ Ilan Katz, ${ }^{6}$ \\ Sally Brinkman, ${ }^{7,8}$ Geoffrey Woolcock, ${ }^{9,10}$ Billie Giles-Corti ${ }^{4}$
}

To cite: Goldfeld S, Villanueva $\mathrm{K}$, Tanton $\mathrm{R}$, et al. Kids in Communities Study (KiCS) study protocol: a cross-sectional mixed-methods approach to measuring community-level factors influencing early child development in Australia. BMJ Open 2017;7:e014047. doi:10.1136/bmjopen-2016014047

- Prepublication history for this paper is available online To view these files please visit the journal online (http://dx.doi.org/10.1136/ bmjopen-2016-014047)

Received 29 August 2016 Accepted 8 November 2016

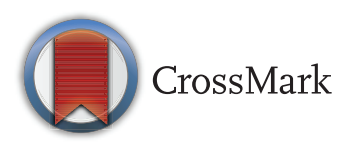

For numbered affiliations see end of article.

Correspondence to Professor Sharon Goldfeld; Sharon.goldfeld@rch.org.au

\section{ABSTRACT}

Introduction: Healthy childhood development in the early years is critical for later adult health and wellbeing. Early childhood development (ECD) research has focused primarily on individual, family and school factors, but largely ignored community factors. The Kids in Communities Study (KiCS) will test and investigate community-level influences on child development across Australia.

Methods and analysis: Cross-sectional mixedmethods study exploring community-level effects in 25 Australian local communities; selection based on community socioeconomic status (SES) and ECD using the Australian Early Development Census (AEDC), a population measure of child development, to create a local community 'diagonality type', that is, those performing better or worse (off-diagonal), or as expected (on-diagonal) on the AEDC relative to their SES. Data collection includes stakeholder interviews, parent and service provider focus groups, and surveys with general community residents and service providers, mapping of neighbourhood design and local amenities and services, analysis of policy documents, and the use of existing sociodemographic and early childhood education and care data. Quantitative data will be used to test associations between local community diagonality type, and ECD based on AEDC scores. Qualitative data will provide complementary and deeper exploration of these same associations.

Ethics and dissemination: The Royal Children's Hospital Human Research Ethics Committee approved the study protocol (\#30016). Further ethics approvals were obtained from State Education and Health departments and Catholic archdioceses where required. ECD community-level indicators will eventually be derived and made publically available. Findings will be published in peer-reviewed journals, community reports, websites and policy briefs to disseminate results to researchers, and key stakeholders including policymakers, practitioners and (most importantly) the communities involved.

\section{INTRODUCTION}

Healthy child development is the foundation for human capital and the basis for future community and economic development. ${ }^{1} \mathrm{~A}$ significant body of convergent research emphasises the importance of the prenatal and early years for health and developmental outcomes throughout the life course. ${ }^{2}$ For a growing number of children, suboptimal developmental trajectories are well established by the time they start school, and become increasingly difficult and costly to modify with the passage of time. ${ }^{3}$ Thus, investing in young children is important for the prevention of disease later in life and contributes to their full participation in society as healthy and productive adults. ${ }^{45}$

Alongside this research, there is intervention, epidemiological, sociological and qualitative evidence all suggesting that local environments are important in supporting the family capacity necessary to raise children in ways that promote good developmental outcomes. ${ }^{6}{ }^{7}$ The neighbourhoods or communities in which people live appears to impact health and well-being. ${ }^{8}$ While 'neighbourhood' is often used in other studies, in the Australian context 'neighbourhood' and 'community' are often used interchangeably (these terms are further defined on page 9).$^{7}$ The research into neighbourhood effects on children was originally motivated by the observation that disadvantage seemed geographically concentrated and intergenerational. This then established the relationship between neighbourhood socioeconomic status (SES) and a number of children's health and developmental outcomes. ${ }^{9}$ Longitudinal research suggested structural characteristics such as poverty and demography were 
mediated through community-level social processes that influenced the functioning of families and children. ${ }^{10} 11$ Today, however, there is still limited understanding of the modifiable community-level factors likely to benefit outcomes for young children despite socioecological frameworks suggesting there are multiple levels of influence (individual, family, community) on early child development (ECD). ${ }^{12}{ }^{13}$ Investigating these influences is thought best undertaken through a combination of quantitative and qualitative methods that can test these multiple influences on ECD. ${ }^{14} 15$

The Kids in Communities Study (KiCS) collaboration consists of six chief investigators (CIs) from Australian Universities, and investigators from academic, nongovernment and government sectors (herein 'partner investigators' (PIs)). It was established in 2007 to investigate the relationship between community-level socioeconomic, demographic and social processes and ECD using a multidisciplinary and multimethod approach. The conceptual framework that guides KiCS is derived from the social and health sciences and includes five community domains of influence: services, social, socioeconomic, physical environment and governance (see figure 1, from Goldfeld $e t a l^{7}$ ). It was designed to wholly encompass community-level processes that take into account conceptual thinking to date including seminal work from Sampson et $a l^{16}$ and Leventhal and Brooks-Gunn. $^{10}$ Beyond the sociodemographic characteristics of residents, such theoretical models include elements of social ties/interaction (eg, social capital and ties between neighbours), institutional resources (eg, availability and accessibility of affordable, quality services), routine activities (eg, patterns of land use and daily routine activities such as the location of schools). Further information about the theoretical

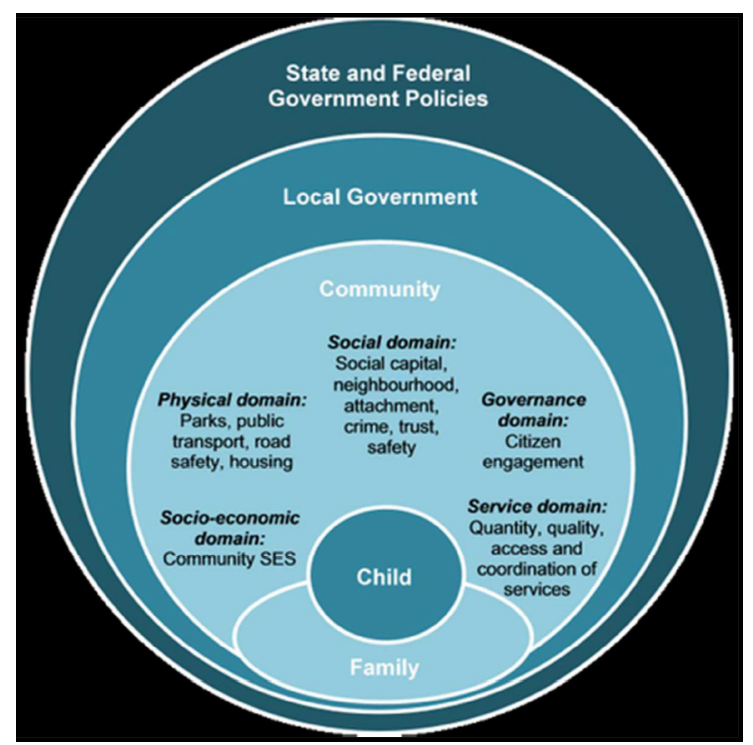

Figure 1 The conceptual framework. KiCS, Kids in Communities Study; SES, socioeconomic status. Adapted from Goldfeld et al'. underpinnings of the KiCS framework and the description of the five community domains, is described in Goldfeld $e t a l^{7}$ The five community domains that form the KiCS framework is derived from the literature and recognises the community platform as a potential point of intervention for better ECD outcomes, through providing strong, healthy communities. ${ }^{7}$ The study aims to investigate how modifiable community-level factors in these five inter-related domains influence ECD using the Australian Early Development Census (AEDC); a population measure of $\mathrm{ECD}$, and an adaptation of the Canadian Early Development Index (EDI). ${ }^{17}$

In 2009, 2012 and 2015 the Australian government implemented the AEDC across Australia for children in their first year of full-time schooling. The AEDC measures five domains of development: physical, social competence, emotional maturity, language and cognitive skills and communication. In 2012, data on $96.5 \%$ $(n=289$ 973) of Australian children were captured by the AEDC; $22.0 \%$ of children were developmentally vulnerable in one or more AEDC domains. ${ }^{18}$ There was geographic variation in ECD, with higher rates of developmental vulnerability typically found in poorer areas; $15.2 \%$ of young children living in the least disadvantaged areas were developmentally vulnerable on one or more AEDC domain, compared with $31.7 \%$ of young children who lived in the most disadvantaged areas. ${ }^{18}$

Examination of national results, however, identified a number of communities where children's developmental results did not appear to align with the community SES as would be expected (ie, these areas were doing better or worse than expected). Further investigation suggested that these 'off-diagonal' communities may well hold great interest when exploring areas for intervention that may benefit or harm children's outcomes. ${ }^{19}$ This approach is central to the current extension of KiCS research. From the initial AEDC data in 2009, a pilot KiCS study funded by the Victorian Health Promotion Foundation (Vic Health) was established to test a series of measures and data collection approaches against the KiCS conceptual framework in two communities in Victoria (VIC), Australia. ${ }^{20}$ The study tested a combination of quantitative (community survey, mapping), and qualitative (interviews and focus groups) approaches to measure community assets and challenges in the context of the AEDC results. For the current study, peer-reviewed funding from a combination of government and nongovernment organisations (2014) enabled KiCS to expand to 25 local communities across five Australian states and territories: VIC, New South Wales (NSW), Queensland (QLD), South Australia (SA) and the Australian Capital Territory (ACT).

This study aims to identify modifiable (potentially amenable to change through policy) community-level factors that influence children's health and developmental outcomes in the 25 areas of high and low disadvantage across Australia. The objectives are to identify key community-level factors that appear to influence ECD 
and to examine how these factors interact in different community contexts with two specific research questions:

- Are any community-level factors consistently related to better outcomes for children, particularly in communities whose outcomes are better or worse than expected for their level of disadvantage (ie, off-diagonal)?

- Of these, what are the best measurable and modifiable community-level factors that influence children's developmental and health outcomes across communities?

\section{METHODS AND ANALYSIS}

To explore community-level influences on ECD, the study focuses on communities where children are developing well and where they are developing poorly relative to the SES of their local community. The study is designed to explore differences and commonalities between on-diagonal and off-diagonal local communities, as well as exploring community-level predictors of ECD (using the AEDC). The research uses a mixedmethods approach (quantitative and qualitative) conducted in three stages: stage 1: site eligibility criteria and recruitment; stage 2: data collection and field work; and stage 3: data analysis and knowledge exchange.

\section{Stage 1: site eligibility criteria and selection}

The definition of 'community'

While the term 'community' may refer to a place or group of people with something in common, and 'neighbourhood' concerns the geographic construct or boundaries, ${ }^{7}$ for this study, our definition of 'local community' aligns with the AEDC nomenclature and geographic boundaries. The AEDC results are publicly reported as an area-level aggregate termed 'local community', ${ }^{21}$ the size of which varies, but in metropolitan and large regional areas, equates to $\sim 10000$ persons per area on average. ${ }^{22} 23$ AEDC local communities are the unit of investigation because these are the smallest areas for which AEDC data are publicly available and pockets of disadvantage can be hidden when larger areas are used. AEDC local communities are clustered within larger AEDC ‘communities' or local government areas.

\section{Site eligibility criteria and selection}

The methodology for local community eligibility and selection is described in detail elsewhere, ${ }^{22}$ but briefly outlined here. The 2009 and 2012 national AEDC data and the Australian Bureau of Statistics (ABS) Socioeconomic Index for Areas Index of Relative Socio-economic Disadvantage (SEIFA-IRSD) have been paired to identify off-diagonal local communities and adjacent on-diagonal counterparts. The SEIFA indexes are a set of indexes of disadvantage produced by the ABS every 5 years using data from the Australian Census. A total of four indexes are produced, and the index used for this analysis was the Index of Relative Socio-economic Disadvantage (IRSD). This index is on a scale of high disadvantage (low values) to low disadvantage (high values). In this index, no indicators of advantage are used, so only indicators like low income, low education, low occupation and public housing are used. These indicators are then combined into one weighted index using a statistical method called principal components analysis to derive the weights for each indicator. More information on the calculation of the SEIFA index can be found in publications from the ABS. ${ }^{24}$ The SEIFA-IRSD has a relative ranking standardised across Australia to a normal distribution with a national average of 1000 , and a SD of $100 .^{25}$ The AEDC data are available from the Australian Department of Education and Training (previously Department of Education, Employment and Workplace Relations). Using a matrix of the AEDC and SEIFA-IRSD scores (quintile to quintile cross tabulation) on-diagonal and off-diagonal local communities are identified.

Using state-based and territory-based SEIFA scores, local communities with low AEDC scores (high developmental vulnerability) despite high SEIFA-IRSD scores (low disadvantage) are deemed 'off-diagonal negative'. In contrast, local communities with high AEDC scores (low developmental vulnerability) despite low SEIFA-IRSD scores (high disadvantage) are considered 'off-diagonal positive'. Those local communities performing as expected are considered 'on-diagonal advantaged' (high AEDC scores, high SEIFA-IRSD scores) or 'on-diagonal disadvantaged' (low AEDC scores, low SEIFA-IRSD scores; see figure 2, adapted from Tanton et $\left.a l^{22}\right)$.

Off-diagonal local communities were then mapped using Geographic Information Systems (GIS) software to identify on-diagonal local communities that were geographically close to off-diagonal local communities (ie, within the same or proximate local government areas). It was assumed that local communities in close proximity to each other are likely to share services (eg, childcare, early childhood programmes) and governance arrangements. In KiCS, there are 25 AEDC local communities, clustered within 12 AEDC communities (local government areas). A snapshot of the local communities, including their diagonality type (on or off diagonal) is shown in table 1 .

\section{Stage 2: data collection and field work}

The five KiCS community domains each have a set of subdomains. A variety of measurement methodologies are used, some of which are designed to capture several domains (ie, cross-domains). The specific domain and cross-domain measures are summarised in table 2 . During the pilot testing a number of cross-domain methods were found to be relatively successful and pragmatic. ${ }^{20}$ Some of these methods have been amended for the main study. Each domain has a mixture of childspecific and broader community-level population 


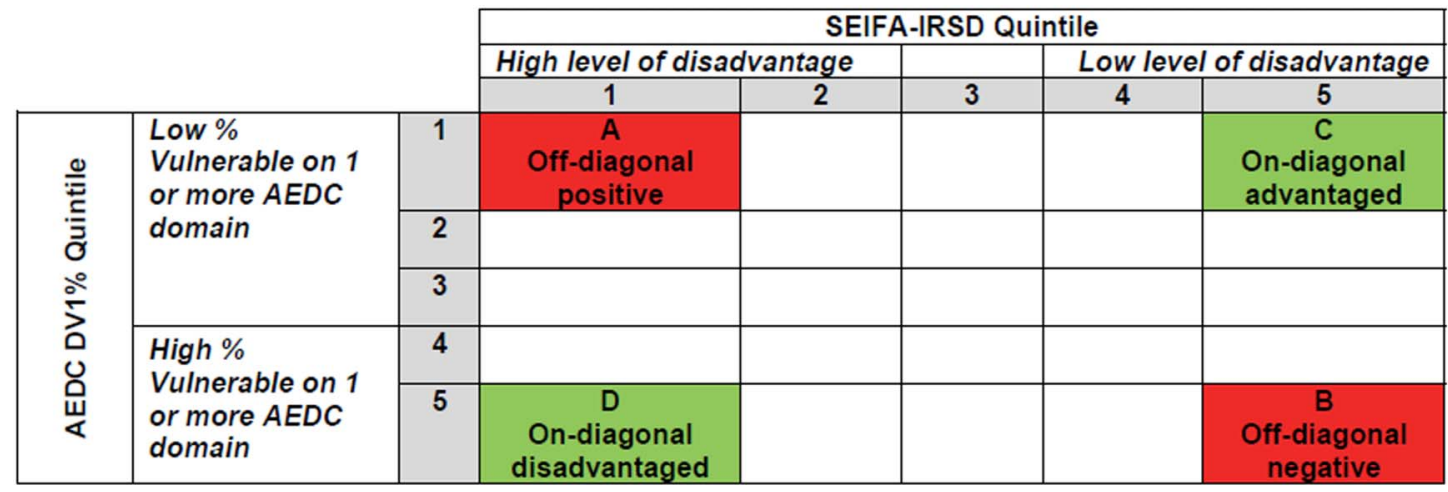

Figure 2 On-diagonal and off-diagonal local communities. Green=on-diagonal; red=off-diagonal. AEDC, Australian Early Development Census; DV1, Developmentally vulnerable on one or more AEDC domain; SEIFA-IRSD, Socioeconomic Index for Areas, Index of Relative Socio-economic Disadvantage. Adapted from Tanton et al. ${ }^{22}$

approaches. The only exception is the service domain where only services for young children and their families will be included, rather than all services. Data collection for the 25 local communities is taking place from March 2014 until December 2016. The complete set of data collection approaches and measures is summarised in tables 2 and 3 and outlined in further detail below.

\section{Recruitment of participants in local communities}

Recruitment of participants for the study is described in detail below under each data collection method. Briefly, state and territory PIs will be approached by the research team to provide recommendations of stakeholders and service provider contacts that may assist with the study. In this way, a snowballing technique ${ }^{26}$ is used to help identify potential participants for the study and/ or those who can assist with recruitment of participants. Desktop analysis (eg, internet searches) is also used to find services and contacts within the communities. Community engagement and participant recruitment for this study relies heavily on the researchers conducting the field work, which involves a complex process of relationship building and trust. In order to prevent stigmatising on-diagonal or off-diagonal communities, the diagonality type of the local community is not mentioned during any form of public engagement with participants.

\section{Qualitative data collection methods}

The qualitative research in this study will explore factors that have previously been difficult to capture due to limited availability of data. A number of concurrent data collection activities will be undertaken. A field researcher in each state and territory is employed to engage with each community and conduct interviews, focus groups and gather policy documents.

Policy analysis: Policy document analysis will: (1) describe the policy context; (2) provide verification or support for other elements of the qualitative study; (3) identify individuals and organisations that are important in services and governance in the local area; and (4) provide history, goals, objectives and substantive context about governance, social capital and service environments in the communities. Policy documents may include: local area and local government documents focused on early childhood (eg, local early years plan); infrastructure reports; consultation reports and local annual reports focused on early childhood (eg, annual reports of key organisations operating in the area). As local communities are clustered within larger AEDC

Table 1 Snapshot of local communities

\begin{tabular}{|c|c|c|c|c|c|c|c|c|}
\hline & \multirow[b]{2}{*}{ State/territory } & \multirow[b]{2}{*}{$\begin{array}{l}\text { Local communities } \\
n=25\end{array}$} & \multicolumn{2}{|c|}{$\begin{array}{l}\text { Geographic } \\
\text { region }\end{array}$} & \multicolumn{2}{|c|}{ Off-diagonal } & \multicolumn{2}{|l|}{ On-diagonal } \\
\hline & & & $\begin{array}{l}\text { Urban } \\
n=18\end{array}$ & $\begin{array}{l}\text { Regional } \\
\mathrm{n}=7\end{array}$ & $\begin{array}{l}\text { Positive } \\
n=8\end{array}$ & $\begin{array}{l}\text { Negative } \\
n=5\end{array}$ & $\begin{array}{l}\text { Advantaged } \\
\mathrm{n}=3\end{array}$ & $\begin{array}{l}\text { Disadvantaged } \\
n=9\end{array}$ \\
\hline 1 & VIC & 6 & 3 & 3 & 1 & 2 & 2 & 1 \\
\hline 2 & NSW & 6 & 6 & 0 & 3 & 0 & 0 & 3 \\
\hline 3 & SA & 4 & 4 & 0 & 1 & 1 & 0 & 2 \\
\hline 4 & QLD & 6 & 2 & 4 & 2 & 1 & 0 & 3 \\
\hline 5 & ACT & 3 & 3 & 0 & 1 & 1 & 0 & 1 \\
\hline
\end{tabular}

Urban/regional status is determined using the ABS remoteness area classification. Local communities as defined by the Australian Early Development Census.

ABS, Australian Bureau of Statistics; ACT, Australian Capital Territory; NSW, New South Wales; QLD, Queensland; SA, South Australia; VIC, Victoria. 


\begin{tabular}{|c|c|c|c|c|c|c|c|c|c|c|}
\hline \multirow[b]{2}{*}{$\begin{array}{l}\text { Community domain and } \\
\text { subdomain/s }\end{array}$} & \multirow[b]{2}{*}{ Description } & \multicolumn{9}{|c|}{ Methodologies } \\
\hline & & $\begin{array}{l}\text { Policy } \\
\text { document }^{*}\end{array}$ & $\begin{array}{l}\text { Stakeholder } \\
\text { interview* }^{*}\end{array}$ & $\begin{array}{l}\text { Parent } \\
\text { focus } \\
\text { group* }\end{array}$ & $\begin{array}{l}\text { Practitioner } \\
\text { focus group* }\end{array}$ & $\begin{array}{l}\text { Service } \\
\text { survey }^{*}\end{array}$ & $\begin{array}{l}\text { Community } \\
\text { survey* }^{*}\end{array}$ & $\begin{array}{l}\text { GIS and } \\
\text { park } \\
\text { audit† }\end{array}$ & $\begin{array}{l}\text { Service } \\
\text { information } \dagger\end{array}$ & $\begin{array}{l}\text { Community } \\
\text { demographics } \dagger\end{array}$ \\
\hline \multicolumn{11}{|l|}{ Physical domain } \\
\hline 1. Public open space & $\begin{array}{l}\text { Objective counts, size, type, quality and proximity to green } \\
\text { space (eg, parks), blue space (eg, water bodies such as } \\
\text { beaches). } † \text { Perceptions of public open space }{ }^{*}\end{array}$ & & $\checkmark$ & $\checkmark$ & $\checkmark$ & & $\checkmark$ & $\checkmark$ & & \\
\hline 2. Public transport & $\begin{array}{l}\text { Objective counts and proximity to bus, tram, rail/train and } \\
\text { ferry stops. } † \text { Perceptions of public transport }{ }^{\star}\end{array}$ & & $\checkmark$ & $\checkmark$ & $\checkmark$ & & $\checkmark$ & $\checkmark$ & & \\
\hline 3. Traffic exposure & $\begin{array}{l}\text { Objective exposure to traffic volume (high vs low). } \\
\text { Perceptions of traffic exposure* }\end{array}$ & & $\checkmark$ & $\checkmark$ & $\checkmark$ & & $\checkmark$ & $\checkmark$ & & \\
\hline 4. Housing & $\begin{array}{l}\text { Objective residential density (number of dwellings/ } \\
\text { residential land area) and proportion of high rise (four or } \\
\text { more storeys) vs Low rise. } † \text { Perceptions of housing }\end{array}$ & & $\checkmark$ & $\checkmark$ & $\checkmark$ & & $\checkmark$ & $\checkmark$ & & $\checkmark$ \\
\hline 5. Destinations and services & $\begin{array}{l}\text { Objective counts of and proximity to places/facilities/ } \\
\text { destinations such as services, childcare, libraries, } \\
\text { community centres and recreation venues. } † \text { Perceptions } \\
\text { of destinations and services }\end{array}$ & & $\checkmark$ & $\checkmark$ & $\checkmark$ & $\checkmark$ & $\checkmark$ & $\checkmark$ & $\checkmark$ & \\
\hline 6. Walkability & $\begin{array}{l}\text { Objective walkability (density, mixed use, connectivity). } \dagger \\
\text { Perceived ease or difficulty of getting to and from } \\
\text { destinations and services, that is, how 'pedestrian friendly' } \\
\text { or 'walkable' the community is 's }\end{array}$ & & $\checkmark$ & $\checkmark$ & $\checkmark$ & & $\checkmark$ & $\checkmark$ & & \\
\hline 7. Crime/incivilities & $\begin{array}{l}\text { Objective crimes against the person in public or property, } \\
\text { total crime rate. }+ \text { Perceptions of crime* }\end{array}$ & & $\checkmark$ & $\checkmark$ & $\checkmark$ & & $\checkmark$ & $\checkmark$ & & $\checkmark$ \\
\hline \multicolumn{11}{|l|}{ Social domain } \\
\hline \multicolumn{11}{|l|}{ 8. Social capital/ties } \\
\hline a. Networks & $\begin{array}{l}\text { Bonding, bridging and linking capital, that is, relationships, } \\
\text { interactions and connections with people. }\end{array}$ & & & $\checkmark$ & $\checkmark$ & & $\checkmark$ & & & \\
\hline b. Participation & Whether people participate in events and activities & & $\checkmark$ & $\checkmark$ & $\checkmark$ & & $\checkmark$ & & & \\
\hline c. Trust & $\begin{array}{l}\text { Personalised trust (feeling able to trust other people } \\
\text { within the community) and generalised trust (feeling able } \\
\text { to trust/have confidence in institutions) }\end{array}$ & & & $\checkmark$ & $\checkmark$ & & $\checkmark$ & & & \\
\hline $\begin{array}{l}\text { d. Perceptions of } \\
\text { community diversity }\end{array}$ & $\begin{array}{l}\text { Perceptions of whether the community is homogeneous } \\
\text { or diverse }\end{array}$ & & $\checkmark$ & $\checkmark$ & $\checkmark$ & & $\checkmark$ & & & \\
\hline \multicolumn{11}{|l|}{ 9. Crime } \\
\hline $\begin{array}{l}\text { a. Community response to } \\
\text { crime }\end{array}$ & $\begin{array}{l}\text { Community response to crime: how people work together } \\
\text { within the community in response to crime or perceived } \\
\text { crime risk }\end{array}$ & & $\checkmark$ & $\checkmark$ & $\checkmark$ & & $\checkmark$ & & & \\
\hline $\begin{array}{l}\text { b. Parental response to } \\
\text { crime }\end{array}$ & $\begin{array}{l}\text { Parent perception of crime and safety: the impact of } \\
\text { parental views on neighbourhood safety on their parenting } \\
\text { behaviour }\end{array}$ & & & $\checkmark$ & & & & & & \\
\hline $\begin{array}{l}\text { c. Perceptions of } \\
\text { neighbourhood safety }\end{array}$ & Perceptions of how safe the community feels & & $\checkmark$ & $\checkmark$ & $\checkmark$ & & $\checkmark$ & & & \\
\hline $\begin{array}{l}\text { d. Domestic violence and } \\
\text { child protection }\end{array}$ & $\begin{array}{l}\text { Perceptions and rates of domestic violence, and number } \\
\text { of children notified in child protection reports }\end{array}$ & & $\checkmark$ & $\checkmark$ & $\checkmark$ & & & & & $\checkmark$ \\
\hline \multicolumn{11}{|l|}{ 10. Neighbourhood attachment } \\
\hline a. Mobility & Individual and community mobility and stability & & $\checkmark$ & $\checkmark$ & $\checkmark$ & & $\checkmark$ & & & $\checkmark$ \\
\hline $\begin{array}{l}\text { b. Perceptions of } \\
\text { neighbourhood } \\
\text { attachment }\end{array}$ & $\begin{array}{l}\text { Perceptions of neighbourhood attachment or how } \\
\text { connected they feel to the community }\end{array}$ & & $\checkmark$ & $\checkmark$ & $\checkmark$ & & $\checkmark$ & & & \\
\hline
\end{tabular}




\begin{tabular}{|c|c|c|c|c|c|c|c|c|c|c|}
\hline \multirow[b]{2}{*}{$\begin{array}{l}\text { Community domain and } \\
\text { subdomain/s }\end{array}$} & \multirow[b]{2}{*}{ Description } & \multicolumn{9}{|c|}{ Methodologies } \\
\hline & & $\begin{array}{l}\text { Policy } \\
\text { document }^{*}\end{array}$ & $\begin{array}{l}\text { Stakeholder } \\
\text { interview* }\end{array}$ & $\begin{array}{l}\text { Parent } \\
\text { focus } \\
\text { group }\end{array}$ & $\begin{array}{l}\text { Practitioner } \\
\text { focus group* }\end{array}$ & $\begin{array}{l}\text { Service } \\
\text { survey* }\end{array}$ & $\begin{array}{l}\text { Community } \\
\text { survey* }^{*}\end{array}$ & $\begin{array}{l}\text { GIS and } \\
\text { park } \\
\text { audit† }\end{array}$ & $\begin{array}{l}\text { Service } \\
\text { informationt }\end{array}$ & $\begin{array}{l}\text { Community } \\
\text { demographics } †\end{array}$ \\
\hline $\begin{array}{l}\text { 11. Child friendliness } \\
\text { a. Perceptions of child } \\
\text { friendliness }\end{array}$ & $\begin{array}{l}\text { Perceptions of whether people in the community are } \\
\text { perceived as being well disposed to children in public } \\
\text { places, and whether the community is perceived as a } \\
\text { 'good' place to raise children }\end{array}$ & & $\checkmark$ & $\checkmark$ & $\checkmark$ & & $\checkmark$ & & & \\
\hline \multirow{2}{*}{$\begin{array}{l}\text { Sociodemographic domain } \\
\text { 12. Community } \\
\text { sociodemographic status } \\
\text { 13. Community demographics }\end{array}$} & As defined by the ABS SEIFA IRSD & & $\checkmark$ & $\checkmark$ & $\checkmark$ & & & & & $\checkmark$ \\
\hline & $\begin{array}{l}\text { Includes: age profile, education, employment, ethnic and } \\
\text { cultural diversity, household types, housing affordability, } \\
\text { income }\end{array}$ & & $\checkmark$ & $\checkmark$ & $\checkmark$ & & $\checkmark$ & & & $\checkmark$ \\
\hline \multicolumn{11}{|l|}{$\begin{array}{l}\text { Service domain } \\
\text { 14. Quality }\end{array}$} \\
\hline \multirow{2}{*}{$\begin{array}{l}\text { a. Accreditation } \\
\text { b.Perceptions of quality }\end{array}$} & Accreditation and licensing & & & & & & & $\checkmark$ & $\checkmark$ & \\
\hline & $\begin{array}{l}\text { Perceptions about quality of service, quality of care, } \\
\text { welcoming staff, physical condition of service. This refers } \\
\text { to how 'good' the service is perceived for children and } \\
\text { families. }\end{array}$ & & $\checkmark$ & $\checkmark$ & $\checkmark$ & & & & & \\
\hline \multicolumn{11}{|c|}{ 근 } \\
\hline a. Number of services & $\begin{array}{l}\text { Objective counts of number of services in the area. } \dagger \\
\text { Perceptions of number of services }{ }^{*}\end{array}$ & & $\checkmark$ & $\checkmark$ & $\checkmark$ & & $\checkmark$ & $\checkmark$ & $\checkmark$ & \\
\hline b. Number per capita & Objective number of services per population $\dagger$ & & & & & & & $\checkmark$ & $\checkmark$ & $\checkmark$ \\
\hline c. Usage & Client use of the service & & $\checkmark$ & $\checkmark$ & $\checkmark$ & & $\checkmark$ & & $\checkmark$ & \\
\hline \multicolumn{11}{|l|}{ 16. Access to services } \\
\hline a. Opening hours & Opening hours of the service & & $\checkmark$ & $\checkmark$ & $\checkmark$ & & & & $\checkmark$ & \\
\hline b. Cost & Cost of what clients/patients pay to use the service & & $\checkmark$ & $\checkmark$ & $\checkmark$ & & & & $\checkmark$ & \\
\hline c. Capacity & Open to new clients/patients, number of vacancies & & $\checkmark$ & $\checkmark$ & $\checkmark$ & & & & $\checkmark$ & \\
\hline d. Waiting lists & Whether people have to wait to access a service & & $\checkmark$ & $\checkmark$ & $\checkmark$ & & & & $\checkmark$ & \\
\hline \multicolumn{11}{|l|}{ 17. Coordination } \\
\hline a. Co-locations & Whether the service is co-located with other services & & $\checkmark$ & & $\checkmark$ & $\checkmark$ & & $\checkmark$ & & \\
\hline $\begin{array}{l}\text { b. Collaborations/ } \\
\text { networks/partnerships }\end{array}$ & $\begin{array}{l}\text { Partnerships and collaborations at the service } \\
\text { implementation level }\end{array}$ & & $\checkmark$ & & $\checkmark$ & $\checkmark$ & & & & \\
\hline \multicolumn{11}{|l|}{ Governance domain } \\
\hline \multicolumn{11}{|l|}{ 18. Context and characteristics } \\
\hline a. History & $\begin{array}{l}\text { Historical factors and events including environmental } \\
\text { events that impact on the current arrangements including } \\
\text { agenda and priorities, partnerships and collaborations }\end{array}$ & $\checkmark$ & $\checkmark$ & & & & & & & \\
\hline b. Multilevel governance & $\begin{array}{l}\text { Characteristics of governance groups and/or community } \\
\text { governance practices, including practices for } \\
\text { decision-making. This refers to 'vertical' governance-that } \\
\text { is, between levels of organisations }\end{array}$ & $\checkmark$ & $\checkmark$ & & & & & & & \\
\hline $\begin{array}{l}\text { c. Priorities, policies and } \\
\text { programmes }\end{array}$ & $\begin{array}{l}\text { Key policies or programmes relating to children. Agenda } \\
\text { and priorities that are currently (or recently) being pursued } \\
\text { by policymakers, partnerships and collaborations in the } \\
\text { community. Includes mention of priorities not specifically } \\
\text { about children }\end{array}$ & $\checkmark$ & $\checkmark$ & & & & & & & \\
\hline
\end{tabular}




\begin{tabular}{|c|c|c|c|c|c|c|c|c|c|c|}
\hline \multirow[b]{2}{*}{$\begin{array}{l}\text { Community domain and } \\
\text { subdomain/s }\end{array}$} & \multirow[b]{2}{*}{ Description } & \multicolumn{9}{|c|}{ Methodologies } \\
\hline & & $\begin{array}{l}\text { Policy } \\
\text { document }^{*}\end{array}$ & $\begin{array}{l}\text { Stakeholder } \\
\text { interview* }^{*}\end{array}$ & $\begin{array}{l}\text { Parent } \\
\text { focus } \\
\text { group }\end{array}$ & $\begin{array}{l}\text { Practitioner } \\
\text { focus group* }\end{array}$ & $\begin{array}{l}\text { Service } \\
\text { survey }^{*}\end{array}$ & $\begin{array}{l}\text { Community } \\
\text { survey }^{\star}\end{array}$ & $\begin{array}{l}\text { GIS and } \\
\text { park } \\
\text { audit } \dagger\end{array}$ & $\begin{array}{l}\text { Service } \\
\text { informationt }\end{array}$ & $\begin{array}{l}\text { Community } \\
\text { demographics } †\end{array}$ \\
\hline \multicolumn{11}{|c|}{ 19. Macro/meso policy environment (context) } \\
\hline $\begin{array}{l}\text { a. Role of federal and } \\
\text { state government } \\
\text { locally, involvement of } \\
\text { portfolio staff locally }\end{array}$ & $\begin{array}{l}\text { The involvement and incidence of Federal and State } \\
\text { programmes and requirements in the area }\end{array}$ & $\checkmark$ & $\checkmark$ & & & & & & & \\
\hline $\begin{array}{l}\text { b. Policies supporting/ } \\
\text { requiring governance } \\
\text { coordination }\end{array}$ & $\begin{array}{l}\text { Federal and State requirements for coordination of } \\
\text { governance }\end{array}$ & $\checkmark$ & $\checkmark$ & & & & & & & \\
\hline \multicolumn{11}{|c|}{ 20. Representation and demographic effects-local } \\
\hline $\begin{array}{l}\text { a. Citizen involvement in } \\
\text { decision-making }\end{array}$ & $\begin{array}{l}\text { Transparent/accountable/responsive structures that have } \\
\text { the ability to reflect community-level interests and ensure } \\
\text { everyone has the right to have a say. The way that } \\
\text { involvement is facilitated in the community including } \\
\text { membership of organisations and decision-making bodies. } \\
\text { Also references to inclusion or exclusion for groups and/or } \\
\text { individuals }\end{array}$ & & $\checkmark$ & $\checkmark$ & $\checkmark$ & & $\checkmark$ & & & \\
\hline \multicolumn{11}{|c|}{ 21. Decision-making and leadership_local } \\
\hline a. Common agenda & $\begin{array}{l}\text { How is the local agenda agreed and is there general } \\
\text { agreement or are there high levels of conflict-specifically } \\
\text { referring to partnerships and coordination }\end{array}$ & $\checkmark$ & $\checkmark$ & & & & & & & \\
\hline $\begin{array}{l}\text { b. Data for } \\
\text { decision-making }\end{array}$ & $\begin{array}{l}\text { Any reference to data or evidence used for the purpose of } \\
\text { decision-making for policy }\end{array}$ & $\checkmark$ & $\checkmark$ & & & & & & & \\
\hline c. Key leaders & $\begin{array}{l}\text { Involves individuals and organisations that are making a } \\
\text { particular contribution, have a role in decision-making }\end{array}$ & $\checkmark$ & $\checkmark$ & $\checkmark$ & $\checkmark$ & & & & & \\
\hline $\begin{array}{l}\text { d. Resources, rules, } \\
\text { roles, structures }\end{array}$ & $\begin{array}{l}\text { Local arrangements for the coordination of } \\
\text { decision-making, policies and programmes and their } \\
\text { implementation }\end{array}$ & $\checkmark$ & $\checkmark$ & & & & & & & \\
\hline
\end{tabular}


Table 3 Summary of methodologies and sample population

\begin{tabular}{|c|c|c|c|c|}
\hline Method & Purpose & Domains & Target sample & Participants \\
\hline Policy analysis & $\begin{array}{l}\text { Policy analysis is particularly important for the } \\
\text { governance domain. Policy documents and grey } \\
\text { literature (identified from discussions with } \\
\text { partners, and internet searches) will be } \\
\text { analysed to understand more about the } \\
\text { governance processes that may influence early } \\
\text { childhood outcomes }\end{array}$ & Governance & $\begin{array}{l}120 \text { policy documents (ie, } \sim 10-12 \text { per } \\
\text { AEDC community) }\end{array}$ & Not applicable \\
\hline $\begin{array}{l}\text { Stakeholder } \\
\text { interview }\end{array}$ & $\begin{array}{l}\text { The purpose of the semistructured stakeholder } \\
\text { interviews is to obtain an in-depth } \\
\text { understanding of governance structures and } \\
\text { coordination mechanisms }\end{array}$ & $\begin{array}{l}\text { Governance and } \\
\text { service }\end{array}$ & $\begin{array}{l}150 \text { stakeholder interviews (ie, 10-15 } \\
\text { per AEDC community) }\end{array}$ & $\begin{array}{l}\text { Individuals with a leadership } \\
\text { role in the community and/or } \\
\text { have significant local } \\
\text { knowledge and contacts }\end{array}$ \\
\hline Parent focus group & $\begin{array}{l}\text { The parent focus group/s aim to obtain a better } \\
\text { understanding of parents' views about their } \\
\text { community }\end{array}$ & $\begin{array}{l}\text { Governance, service, } \\
\text { physical, social, } \\
\text { socioeconomic }\end{array}$ & $\begin{array}{l}25 \text { parent focus groups (ie, } 1 \text { per AEDC } \\
\text { local community) }\end{array}$ & $\begin{array}{l}\text { Parents of young children } 0- \\
8 \text { years old }\end{array}$ \\
\hline $\begin{array}{l}\text { Practitioner focus } \\
\text { group }\end{array}$ & $\begin{array}{l}\text { The practitioner (service provider) focus groups } \\
\text { will provide an in-depth perspective of the five } \\
\text { community domains from local community } \\
\text { professionals }\end{array}$ & $\begin{array}{l}\text { Governance, service, } \\
\text { physical, social, } \\
\text { socioeconomic }\end{array}$ & $\begin{array}{l}25 \text { practitioner focus groups (ie, } 1 \text { per } \\
\text { AEDC local community) }\end{array}$ & Service providers \\
\hline Service survey & $\begin{array}{l}\text { The purpose of the service survey is to } \\
\text { understand more about local service networks } \\
\text { and service coordination }\end{array}$ & Service & $\begin{array}{l}1 \text { per service type in each AEDC local } \\
\text { community }\end{array}$ & $\begin{array}{l}\text { Service providers of early years } \\
\text { services }\end{array}$ \\
\hline $\begin{array}{l}\text { Service } \\
\text { information }\end{array}$ & $\begin{array}{l}\text { Service information on service quantity, access } \\
\text { and quality is obtained through existing data } \\
\text { and service providers }\end{array}$ & Service & $\begin{array}{l}\text { Collected on all ECD services within } \\
\text { each AEDC local community }\end{array}$ & $\begin{array}{l}\text { Service providers of years } \\
\text { services }\end{array}$ \\
\hline Community survey & $\begin{array}{l}\text { The community survey aims to collect data on } \\
\text { local resident views about what their community } \\
\text { is like to live in }\end{array}$ & $\begin{array}{l}\text { Governance, service, } \\
\text { physical, social, } \\
\text { socioeconomic }\end{array}$ & $\begin{array}{l}25000 \text { surveys (ie, } 10000 \text { per AEDC } \\
\text { local community) will be distributed to a } \\
\text { random sample of residents. A } 35 \% \\
\text { response rate is required. }\end{array}$ & $\begin{array}{l}\text { General community residents } \\
\text { (not necessarily parents of } \\
\text { young children) }\end{array}$ \\
\hline GIS and park audit & $\begin{array}{l}\text { Using GIS allows objective assessment of the } \\
\text { physical structure (urban design layout) of the } \\
\text { local community; including its physical layout } \\
\text { and access (proximity and quantity) to services } \\
\text { and destinations }\end{array}$ & Physical & $\begin{array}{l}25 \text { AEDC local communities. All parks } \\
\text { within each local community will be } \\
\text { measured for park 'quality'. }\end{array}$ & Not applicable \\
\hline $\begin{array}{l}\text { Community } \\
\text { demographics and } \\
\text { data }\end{array}$ & $\begin{array}{l}\text { Where possible, existing data on the community } \\
\text { will be sourced. For example, community } \\
\text { demographics are sourced from the Australian } \\
\text { Bureau of Statistics } 2011 \text { Census data }\end{array}$ & Socioeconomic & 25 AEDC local communities & Not applicable \\
\hline
\end{tabular}


communities (ie, local government area) likely to share the same governance structure, 10-12 key policy documents will be obtained for each community. A desktop search and sourcing materials through stakeholders and PIs will be used to find policy documents available in the public domain.

Stakeholder interviews: The semistructured stakeholder interviews aim to obtain a deeper understanding of the community context, local governance, how stakeholders work together and member attitudes regarding children and families. Stakeholders will be individuals who either play a leadership role in the community and/or have significant local knowledge and contacts, for example, community champions, managers of early year services. Approximately 10-12 key stakeholders in each AEDC community (local government area) will be approached (ie, $\sim 120$ in total). They will be identified using professional networks of community and government-based partners on the study. Using a snowball sampling methodology, ${ }^{27}$ interviewees will be asked to recommend other potential key stakeholders (preferably with different views from them) within their professional networks. ${ }^{28}$ Interviews will be conducted face-to-face in community settings or offices of individuals being interviewed, and will be audio recorded and transcribed. Phone interviews may occur if face-to-face interviews are not possible.

Focus groups: The focus groups will explore: (1) the degree of 'social capital' and 'community cohesiveness' (particularly attitudes towards and experiences of young children and their families); (2) the resources available to support the development of these social conditions; (3) views on quality, access and use of local services and amenities; and (4) attitudes towards local civic participation and local governance arrangements. For each local community, one focus group will be conducted with: (1) parents of young children (at least one child below 8 years old); and (2) service providers or practitioners. Each focus group will include $8-10$ participants.

Participants for the focus groups will be recruited initially through PIs who have links to service providers and to families with young children in the community. For the parent focus groups, playgroup facilitators are asked permission to invite parents who participate in local playgroups to take part in the study. It is anticipated that the field researchers will piggyback on existing playgroups in the study communities for ease of running focus groups. To further assist with parent recruitment, flyers (simple, easy-to-read flyer) for the focus groups may be posted at community organisations (eg, public libraries and community centres) or circulated through local networks. Focus groups will run for $\sim 1-1.5$ hours, and a $\$$ A25 gift voucher will be provided to parent participants in recognition of their involvement in the study. Focus groups will be held at a local venue (eg, community centre or school). Focus groups will be audio recorded and transcribed.
Quantitative data collection

The quantitative approaches of this study will provide a descriptive snapshot of the communities and will contribute to the modelling of estimated differences between communities. These data will complement the qualitative data to provide a more detailed understanding of each local community in order to address each research questions.

Service data and surveys: The service data collected will include quantity, quality, access and coordination for services related to children and families. Desktop analysis will be used to obtain information such as staff capacity, clientele, opening hours, accreditation, etc. To obtain data on service coordination and local networks, local service providers such as government representatives, school principals, general practitioners and playgroup leaders will be asked to complete a service survey online or in hardcopy at a focus group in which they attend. The aim is to obtain a service survey from at least one service provider representative from each service type within the local community (eg, general practitioner, primary school and childcare).

Community surveys: The community survey is designed to elicit general residents' (over 18 years old) perceptions and attitudes about the community. The survey includes questions of relevance to the service, social, physical and governance domains, using a combination of: (1) validated items from existing surveys; ${ }^{29-31}$ (2) derived items where existing items do not exist. Brief demographic questions will also be asked. The items are pilot tested for face validity (content and structure), and test-retest reliability ( 2 weeks apart), with a convenience sample of staff members at the Melbourne Royal Children's Hospital (n=32 participants). Items which have acceptable reliability (ie, $\kappa$ or intraclass correlation $>0.60$ ) will be included in the final community survey instrument. $^{32}$

Sample size: To have a representative sample of general community members (over 18 years old) at the smallest possible geography, a random sample of residential addresses will be requested from the Australian Electoral Commission (AEC), an organisation responsible for electoral records. In Australia, it is mandatory to vote in most State and all Federal elections, thus all residents eligible to vote (ie, those over 18 years old) are included on the electoral roll. A sample size of at least 350-390 surveys per local community is required at $95 \%$ confidence level, and 0.05 CI. Owing to budget and resources, the AEC will provide a random sample of 1000 residential addresses (name of resident and address information only) per local community (25 000 addresses in total). Thus, a $35-39 \%$ response rate is required.

Survey distribution: The community survey will be distributed in three waves, an approach adapted from the Dillman method. ${ }^{33}$ This approach (eg, prenotification, survey, postreminder) is considered best practice for enhancing response rates to large-scale population 
health surveys. Respondents have the option of completing surveys online via a web link to Research Electronic Data Capture (REDCap), an online data capture tool hosted on a secure server, ${ }^{34}$ by phone or returning the survey in a reply paid envelope. Participants will be deemed as having provided implied consent if they complete and return the anonymous survey, and will be offered a chance to win one of three $\$ A 300$ supermarket gift vouchers.

Wave 1: prenotification letter (a month before survey distribution): wave 1 contains a letter inviting the resident to complete the survey online (or by phone). Wave 2: main survey (1 month after prenotification): wave 2 will only contain participants who did not respond to wave 1. Wave 2 involves posting a hardcopy version of the survey and reply paid envelope. Participants still have the option of completing the survey online or by phone. Wave 3: postsurvey reminder (1 month after main survey distribution): this stage will only contain remaining participants who did not respond in waves 1 and 2. Wave 3 involves posting a letter to remind them to complete the survey online or by phone (another hardcopy version of the survey will not be posted).

GIS and park audits: GIS software (ESRI ArcGIS v10; ArcGIS v10 [program]. Redlands, California, 2010) will be used to calculate spatial measures of the physical environment within and surrounding each local community. Measures include those aligned with the physical and service subdomains (table 2), and include measures previously found to be associated with child and adult behavioural and health outcomes (eg, walking, cycling and obesity). ${ }^{35}{ }^{36}$ These include measures of walkability, or pedestrian friendliness of the environment; and distance to, and count of services (eg, libraries, maternal and child health services and childcare services), facilities (eg, recreation centres, community centers), and other venues (eg, parks). Where available, data from government and non-government sources are being used to calculate the measures. GIS measures are calculated at two geographic scales and linked to the outcome data to enable simple and more complex analyses, respectively: (1) local community level ( 10 000 persons on average); and (2) the ABS statistical area level 1 (SA1), an area of $\sim 400$ persons on average. ${ }^{23}$

Detailed 'quality' data will be collected on local parks. Previous research suggests that residents do not necessarily travel to their closest park. Rather, they travel further distances to use a park with better facilities and features. ${ }^{37}$ Therefore, features of parks in each local community will be audited using a validated remote desktop park auditing tool. ${ }^{38}$ The 'Public Open Space Desktop Auditing Tool' (POSDAT) uses a combination of GIS software, Google Earth and Google Street view to capture park features and attributes. Park features include the presence or number of amenities (eg, seating and benches, barbeque facilities, playgrounds), aesthetics (eg, water features, shade along paths) and sporting activities (eg, tennis courts, basketball courts).
To create a child/family-friendly 'park quality' score for each park, each feature will be weighted and summed; this has previously been done with both adults, ${ }^{39}$ and adolescents. $^{40}$

Community demographics: The Australian Census occurs every 5 years. Existing information available from the ABS on the sociodemographics of residents within each local community will be obtained.

\section{Stage 3: data analysis}

Combining qualitative with quantitative methods (mixed methods) can provide a deeper and more comprehensive understanding of complexities underlying the potential pathways in which communities impact ECD. ${ }^{41}$ The mixed-methods investigations undertaken through this study will determine whether there are any consistent community-level factors associated with on-diagonal and off-diagonal communities.

Outcomes: There are two key outcomes. The first outcome is the local community 'diagonality' types (see A, B, C and D, in figure 2). The 'off-diagonal' local community types are those areas that are doing better (offdiagonal positive) or worse (off-diagonal negative) than their relative SES. These will be compared with the two on-diagonal local community types, that is, those areas that are doing as expected relative to their SES.

The second outcome is the proportion of children developmentally vulnerable on one or more AEDC domains, which is the same measure used for identifying the off-diagonal communities. The AEDC data are collected by teachers who complete an online checklist for each child in their first year of formal full-time school ( $~ 5$ years old) covering the five ECD areas previously noted of physical development, social competence, emotional maturity, language, and cognitive development (eg, academic learning), and general knowledge and communication. ${ }^{17}$ Children are scored on each of these domains, and categorised as 'developmentally vulnerable' ( $\leq 10$ th centile), 'developmentally at risk' (between 10th and 25th centiles) and 'developmentally on track' $(\geq 25 \text { th centile })^{17}$ Children who are developmentally at risk on one or more ECD domain (ie, DV1) is typically reported in AEDC publications. Within the 25 local communities, there is AEDC information on 2598 children.

Analysis: The analyses will be conducted in two phases. Phase 1 will include descriptive analyses examining patterns by diagonality type (ie, the four on-diagonal and off-diagonal groups). Qualitative and quantitative descriptive analyses will be undertaken concurrently. Patterns of community factor convergence and divergence that differentiate on-diagonal and off-diagonal communities will be explored. Phase 2 will include more complex analyses (eg, multilevel modelling) using the breadth of the quantitative data.

Analysis phase 1: All transcribed qualitative data and field notes will be entered into QSR International's Nvivo V.11 software, designed to assist with organising and coding qualitative data (NVivo qualitative data 
analysis Software Version 11 [program]: QSR International Pty Ltd, 2015). Owing to the large amount of qualitative data, content analysis will be applied; this requires a deductive approach, where predefined categories are used to help 'code' the data. A comprehensive coding framework aligned with the study's domains and indicators was developed by the research team. Information that does not 'fit' within the existing coding framework but may be important to the study will be coded as 'other useful information'. To ensure analytical rigour and consensus, issues will be discussed and consolidated through regular team coding discussions; such approaches have been used in previous studies. ${ }^{42-44}$ The analysis techniques will identify domains and factors which facilitate or hinder optimal ECD in the on-diagonal and off-diagonal communities. The proposed approach will be used to organise study findings and to create cluster themes that support the quantitative analysis and provide more detail on why the differences between local communities might exist. Any differences by diagonality type will be described and will provide further explanations for the quantitative findings. The quantitative data analyses (see below) will be explored concurrently with qualitative data analyses to determine areas of convergent and divergent results in regard to the on-diagonal and off-diagonal community comparisons. The qualitative data will also help to generate hypotheses that can be tested further with quantitative data.

Data reduction techniques (eg, cluster analyses and scales) will be used to combine quantitative variables and identify scores for the community domains and subdomains driving the differences between on-diagonal and off-diagonal communities across each of the domains. Data will include multiple measures from the ABS and other sources, the service and community surveys, and GIS. Owing to the small sample size, a priority will be to provide descriptive statistics of local community-level data using Stata (Stata Statistical Software: Release 13 [program]. TX: StataCorp LP.: College Station, 2013). However, in addition, we will also compare on-diagonal and off-diagonal communities using t-tests and $\chi^{2}$ tests of significant differences between means for the community types.

Analysis phase 2: Multilevel modelling of the quantitative data will be undertaken to identify which factors might influence the AEDC (as the outcome measure) in each local community focusing on the ecological framework of neighbourhood and family/individual factors. GIS and sociodemographic data calculated at a smaller geographic level (ie, ABS SA1 or an average of 400 persons per area) and linked to the outcome measures (ie, AEDC DV1 also calculated at the same level) provide the opportunity to conduct additional analyses with a larger sample, exploring the results for all children ( $\mathrm{n}=2598)$ with an AEDC result nested within local communities and communities.

Study governance: The KiCS collaboration currently consists of six CIs from Universities across Australia, and 17 named PIs from a range of non-government and government organisations. The group of six CIs teleconference monthly to ensure consistency in site data collection and general project oversight. All investigators teleconference quarterly to discuss the progress of the study. An in-person meeting of all investigators occurs annually. Field researchers will collect data in study communities in each state and territory, overseen by the CI responsible for that state or territory. Day-to-day coordination of study activities will be performed by the project coordinator based in Melbourne, VIC.

\section{ETHICS AND DISSEMINATION \\ Ethics}

This includes approval for all consent processes necessary for each of the data collection elements. For example, participants of a semistructured interview or focus group are required to provide written consent to be involved. Participants will receive a plain language statement describing the study, and will have the opportunity to ask any questions they may have before signing the informed consent form. For service and community surveys, a completed survey is deemed as having provided consent. All participants may decline participation at any time. Publication of data in all publications and reports will de-identify all participants.

Given the national scope of the study, ethics approval was granted by each state and territory where required. The Education Department in each state and territory approved research conducted in early childhood services and/or government primary schools. Moreover, Catholic archdioceses provided ethics approval for the Catholic primary schools approached by the study. For NSW and QLD only, their State Department of Health approved data collection within the study's local communities. In total, 21 ethics applications were submitted, and 18 were approved $(82 \%)$.

\section{Research dissemination and translation}

Research translation is fundamental to this study and is considered from the outset. The KiCS PIs from a range of non-government and government organisations will assist with translation and dissemination of results to the communities. This study is well placed for a strong and strategic communications and dissemination plan that includes research and community capacity building, and effective research translation in a policy environment.

In addition to standard academic outputs (eg, manuscripts and conference presentations), it is anticipated that face-to-face or webinar seminars will be held at the local government councils, brief community reports and lay print media (eg, one-page research snapshots) will be used to release local findings to the communities involved. The uptake of the potential community indicators into social policy systems, and practices is imperative. Established ECD dissemination networks with communities, policymakers, practitioners (child 
development, education) and teachers already exist through the AEDC nationally.

\section{DISCUSSION}

The KiCS is setting out to examine community-level effects on young children's development. In doing so, there are a number of 'frontier' approaches necessary to investigate the question of community impact with any level of rigour and potential replicability and utility. The mixed methodologies in this study will enable convergence of qualitative and quantitative findings to provide a more in-depth understanding of the factors associated with ECD outcomes in communities.

Working towards healthy environments for young children and families requires input from a range of stakeholders across multiple disciplines including practitioners and policymakers from urban planning to paediatrics and education sectors. Moreover, community input is vital if communities are to use the findings. The final aim will be to use findings from this study to develop a set of indicators that will have utility for all communities considering how best to impact the development of their children. This will particularly be useful in the Australian setting where the AEDC data are available on a triennial basis. As such, communities may use these findings and indicators to develop more effective programmes and interventions. Indeed, there is increasing global interest in 'place-based' strategies from governments and philanthropic agencies around the world, propelled somewhat by the collective impact community action momentum and the emerging field of prevention science. ${ }^{4}$ While there is policy interest, the availability of rigorous approaches to data collection and indicators, underpinned by theory and tested for associations with ECD outcomes, is limited. Therefore, this study's findings will likely have timely policy utility and knowledge translation impact.

There are a number of limitations to this study. The 25 local communities constitute a small sample size in terms of generalisability. While the utility of existing community quantitative data can be enhanced by complementary qualitative data, even with deeper findings there will be limitations to how generalisable these can be across Australia. It is hoped that future studies will go on to test these approaches in further diverse communities. This approach will strengthen the generalisability while offering pragmatic measures in the interim. GIS data, while a useful analytic tool in examining community-level effects, are currently mainly available only for urban environments. Broader utility for use of GIS in regional communities is yet to be assessed.

The issues of scope and generalisability are a critical consideration for studies of this nature where we are seeking ecological causality. It is encouraging that previous studies in the social sciences have had significant findings from small sample sizes (eg, Coulton et $a l^{45}$ ) when focused on outcomes such as child protection notifications. Indeed our own social environment measures align with these studies and offer opportunities for interesting international comparisons. In a world of practicalities where the rhetoric for community change has outpaced the evidence, it is important to insert some level of measurement rigour that both facilitates the exploration of community understanding and suggests (rather than proves) some level of causal link. Measuring the domains of focus in this study (social, service, governance, physical and sociodemographic) are a real strength of the study. It will make an important contribution to the development of indicators that help communities and governments drive efforts towards better and more equitable developmental outcomes for young children.

\section{Author affiliations}

${ }^{1}$ Department of Paediatrics, University of Melbourne, The Royal Children's Hospital, Parkville, Victoria, Australia

${ }^{2}$ Murdoch Childrens Research Institute, Parkville, Victoria, Australia

${ }^{3}$ Centre for Community Child Health, Royal Children's Hospital, Parkville, Victoria, Australia

${ }^{4}$ McCaughey Community Wellbeing Unit, School of Population and Global Health, University of Melbourne, Carlton, Victoria, Australia

${ }^{5}$ National Centre for Social and Economic Modelling (NATSEM), Institute for Governance and Policy Analysis, University of Canberra, Canberra, Australian Capital Territory, Australia

${ }^{6}$ Faculty of Arts and Social Science, Social Policy Research Centre, University of New South Wales, Sydney, New South Wales, Australia

${ }^{7}$ Fraser Mustard Centre, Telethon Kids Institute, Adelaide, South Australia, Australia

${ }^{8}$ School of Population Health, The University of Adelaide, Adelaide, South Australia, Australia

${ }^{9}$ Wesley Mission Queensland, Chermside, Queensland, Australia

${ }^{10}$ Centre for Evidence and Implementation, West End, Queensland, Australia

Acknowledgements The KiCS collaboration includes the University of Melbourne (lead institution), University of Canberra, University of New South Wales and the University of Western Australia. The partner organisations include: Federal and State governments (Australian Government Department of Education and Training; Australian Bureau of Statistics; Victorian Department of Education and Training; Australian Capital Territory Community Services Directorate; Children's Health Queensland Hospital and Health Service; South Australia Department for Education and Child Development; New South Wales Department of Education and Communities; Queensland Department of Education, Training and Employment; New South Wales Department of Families and Community Services); non-government (The Smith Family, Murdoch Childrens Research Institute, Wesley Mission Brisbane, The Benevolent Society, UnitingCare Children, Young People and Families); other Universities (University of British Columbia, Mount Saint Vincent University and University of California, Los Angeles). The Australian Research Council (ARC) and generous in-kind and financial support from partner organisations are gratefully acknowledged for their contributions to the study, including input into data collection methods, assistance with sourcing data, engaging with the community and ethics processes. SG is supported by a National Health and Medical Research Council (NHMRC) Career Development Fellowship (1082922) and BG-C by a NHMRC Senior Principal Research Fellow Award (1107672). Summer Wood is acknowledged for her contributions to study coordination and set-up. The field researchers including Anna Jones, Melanie Dare, Ju-Lin Lee, Alanna Sincovich, Ashleigh Wilson, Genevieve Smith, and Michelle Tennant are gratefully acknowledged for engaging with communities, recruitment of participants, field work, contributions to methods, and data analysis. Melanie Dare contributed to the selection of communities. Anna Jones assisted with the development of focus group questions, and Rachel Robinson led the development of the 
governance domain and interview questions. Rebecca Roberts contributed to the cleaning, processing and computing of GIS measures. We gratefully acknowledge the participants and stakeholders who have kindly provided their time, resources and input.

Contributors KV developed the first draft of the manuscript based on the existing protocol and contributed to study coordination, data collection, and data cleaning, and analysis. SG is the lead chief investigator $(\mathrm{Cl})$ of the study, along with $\mathrm{RT}$, IK, SB, GW and BG-C as Cls who have contributed to the conception and design of the study. RT, Melanie Dare and SB selected the communities using on-diagonal and off-diagonal methodology, and led the sociodemographic domain. IK led the social domain and developed the focus group questions. SG led the service domain. BG-C and GW led the physical domain; and along with KV, led the conceptualisation of GIS measures. All authors provided critical feedback during manuscript development. Each author has approved the final manuscript.

Funding This study was supported by an Australian Research Council (ARC) Linkage Grant (LP130100411), and financial support from the partner organisations: Australian Government Department of Education and Training; Victorian Department of Education and Training; Australian Capital Territory Community Services Directorate; South Australia Department for Education and Child Development; New South Wales Department of Education and Communities; Queensland Department of Education, Training and Employment; Children's Health Queensland Hospital and Health Service; New South Wales Department of Families and Community Services; The Benevolent Society; and UnitingCare Children, Young People and Families.

Competing interests None declared.

Ethics approval Melbourne Royal Children's Hospital Human Research Ethics Committee (HREC; approval number 30 016).

Provenance and peer review Not commissioned; externally peer reviewed.

Data sharing statement Unpublished data from this study include stakeholder interviews, parent and service provider focus groups, surveys with general community residents and service providers, mapping of neighbourhood design and local amenities and services, analysis of policy documents, and the use of existing sociodemographic and early childhood education and care data. The data are available to the Kids in Communities Study (KiCS) research team.

Open Access This is an Open Access article distributed in accordance with the Creative Commons Attribution Non Commercial (CC BY-NC 4.0) license, which permits others to distribute, remix, adapt, build upon this work noncommercially, and license their derivative works on different terms, provided the original work is properly cited and the use is non-commercial. See: http:// creativecommons.org/licenses/by-nc/4.0/

\section{REFERENCES}

1. Shonkoff JP, Richter L, van der Gaag J, et al. An integrated scientific framework for child survival and early childhood development. Pediatrics 2012;129:e460-e72.

2. Shonkoff JP, Boyce WT, McEwen BS. Neuroscience, molecular biology, and the childhood roots of health disparities: building a new framework for health promotion and disease prevention. JAMA 2009;301:2252-9.

3. Feinstein L, Duckworth K, Sabates R. Education and the family: passing success across the generations: Routledge, 2008.

4. National Academies of Sciences Engineering and Medicine. Advancing the power of economic evidence to inform investments in children, youth, and families. Washington DC: The National Academies Press, 2016.

5. Belfield C. The cost of early school-leaving and school failure. World Bank, 2008

6. Christensen P. Place, space and knowledge: children in the village and the city. In: Lingard B, Nixon J, Ranson S, eds. Transforming learning in schools and communities: the remaking of education for a Cosmopolitan Society. New York: Continuum, 2008:69-84.

7. Goldfeld S, Woolcock G, Katz I, et al. Neighbourhood effects influencing early childhood development: conceptual model and trial measurement methodologies from the Kids in Communities Study. Soc Indic Res 2015;120:197-212.
8. Sallis JF, Floyd MF, Rodríguez DA, et al. Role of built environments in physical activity, obesity, and cardiovascular disease. Circulation 2012;125:729-37.

9. Brooks-Gunn J, Duncan G, Klebanov P, et al. Do neighborhoods influence child and adolescent development. Am J Sociol 1993;9:353-95.

10. Leventhal T, Brooks-Gunn J. The neighborhoods they live in: the effects of neighborhood residence on child and adolescent outcomes. Psychol Bull 2000;126:309-37.

11. Kohen DE, Leventhal T, Dahinten VS, et al. Neighborhood disadvantage: pathways of effects for young children. Child Dev 2008;79:156-69.

12. Bronfenbrenner U. The ecology of human development: experiments by nature and design. Cambridge, MA: Harvard University Press 1979.

13. Vaden-Kiernan M, D'Elio MA, O'Brien RW, et al. Neighborhoods as a developmental context: a multilevel analysis of neighborhood effects on head start families and children. Am J Community Psychol 2010;45:49-67.

14. March D, Susser E. The eco-in eco-epidemiology. Int J Epidemiol 2006;35:1379-83.

15. Muhajarine N, Vu L, Labonte R. Social contexts and children's health outcomes: researching across the boundaries. Crit Public Health 2006;16:205-18.

16. Sampson R, Morenoff J, Gannon-Rowley T. Assessing "Neighbourhood Effects": social processes and new directions in research. Annu Rev Sociol 2002;28:443-78.

17. Brinkman SA, Gregory TA, Goldfeld S, et al. Data resource profile: the Australian Early Development Index (AEDI). Int J Epidemiol 2014;43:1089-96.

18. Australian Government Department of Education. Australian Early Development Census 2012 Summary Report-November 2013. Australia, 2013.

19. Hertzman $C$. Bringing a population health perspective to early biodevelopment: an emerging approach. In: Keating DP, ed. Nature and nurture in early child development. Cambridge: Cambridge University Press, 2012:217-44.

20. Goldfeld S, Mathews T, Brinkman S, et al. The Kids in Communities Study: measuring community level factors influencing children's development. Report for VicHealth. Melbourne: Murdoch Childrens Research Institute, 2010.

21. Commonwealth of Australia Department of Education and Training The Australian Early Development Census 2015. https://www.aedc. gov.au/ (accessed 22 Aug 2016)

22. Tanton R, Dare M, Brinkman S, et al. Identifying off-diagonal communities using the Australian Early Development Census results. Soc Indic Res 2015:1-16.

23. Australian Bureau of Statistics. The Australian Statistical Geography Standard (ASGS), 2013. http://www.abs.gov.au/websitedbs/ D3310114.nsf/home/Australian+Statistical+Geography+Standard +(ASGS) (accessed 09 May 2014).

24. Australian Bureau of Statistics. Socio-Economic Indexes for Areas (SEIFA) 2013. http://www.abs.gov.au/websitedbs/censushome.nsf/ home/seifa?opendocument\&navpos=260 (accessed 27 Jul 2016).

25. Australian Bureau of Statistics. 2033.0.55.001-Census of Population and Housing: Socio-Economic Indexes for Areas (SEIFA), Australia, 20112011 [updated 24 September 2013. http:/ www.abs.gov.au/ausstats/abs@.nsf/mf/2033.0.55.001 (accessed 27 Jul 2016).

26. Atkinson R, Flint J. Accessing hidden and hard-to-reach populations: snowball research strategies. Soc Res Update 2001;33:1-4.

27. Biernacki $P$, Waldorf D. Snowball sampling: problems and techniques of chain referral sampling. Sociol Methods Res 1981;10:141-63.

28. Lewis-Beck MS, Bryman A, Liao TF. Encyclopedia of social science research methods (vols 1-3). Thousand Oaks, CA: SAGE Publications, Inc, 2004.

29. Buckner JC. The development of an instrument to measure neighborhood cohesion. Am J Community Psychol 1988;16:771-91.

30. Kawachi I, Kennedy BP, Glass R. Social capital and self-rated health: a contextual analysis. Am J Public Health 1999;89:1187-93.

31. Christian H, Knuiman M, Bull F, et al. A new urban planning code's impact on walking: the Residential Environments Project. Am J Public Health 2013;103:1219-28.

32. Pallant J. SPSS Survival Manual: a step by step guide to data analysis using SPSS. 3rd edn. Sydney, NSW: Allen \& Unwin, 2007.

33. Dillman DA. Mail and internet surveys: the tailored design method. New York: Wiley, 2000. 
34. Harris PA, Taylor R, Thielke R, et al. A metadata-driven methodology and workflow process for providing translational research informatics support. J Biomed Inform 2009;42:377-81.

35. Ding D, Gebel K. Built environment, physical activity, and obesity: what have we learned from reviewing the literature? Health Place 2012;18:100-5.

36. Ding D, Sallis JF, Kerr J, et al. Neighborhood environment and physical activity among youth: a review. Am J Prev Med 2011;41:442-55.

37. Veitch J, Bagley S, Ball K, et al. Where do children usually play? A qualitative study of parents' perceptions of influences on childrens' active free-play. Health Place 2006;12:383-93.

38. Edwards N, Hooper P, Trapp G, et al. Development of a Public Open Space Desktop Auditing Tool (POSDA): a remote sensing approach. Appl Geography 2013;38:22-30.

39. Giles-Corti $\mathrm{B}$, Broomhall $\mathrm{M}$, Knuiman $\mathrm{M}$, et al. Increasing walking: How important is distance to, attractiveness, and size of public open space? Am J Prev Med 2005;28(2 Suppl 2):169-76.
40. Edwards N, Hooper P, Knuiman M, et al. Associations between park features and adolescent park use for physical activity. Int J Behav Nutr Phys Act 2015;12:1.

41. Fielding NG. Triangulation and mixed methods designs data integration with new research technologies. J Mixed Methods Res 2012;6:124-36.

42. Harry B, Sturges KM, Klingner JK. Mapping the process: an exemplar of process and challenge in grounded theory analysis. Educ Res 2005;34:3-13.

43. Saldana J. An introduction to codes and coding. The coding manual for qualitative researchers. Los Angeles, CA: SAGE, 2009:1-31.

44. Morse J. Critical analysis of strategies for determining rigor in qualitative inquiry. Qual Health Res 2015;25:1212-22.

45. Coulton CJ, Korbin JE, Su M. Neighborhoods and child maltreatment: a multi-level study. Child Abuse Negl 1999;23:1019-40. 